\title{
Student Teachers' Reactions Responding to Students' Disruptive Behaviors: A Case Study in High School Education in Tunisia
}

\author{
Talel Maddeh1,2, Souheil Hermessi², Nabila Bennour ${ }^{1,3}$, Nizar Souissi1,2 \\ ${ }^{1}$ Research Laboratory "Sports Performance Optimization", National Center of Medicine and Science in Sports \\ (CNMSS), Tunis, Tunisia \\ ${ }^{2}$ High Institute of Sport and Physical Education, Manouba University, Ksar-Saïd, Tunisia \\ ${ }^{3}$ High Institute of Sport and Physical Education, Gafsa University, Gafsa, Tunisia \\ Email: nabilabennour2007@yahoo.fr
}

Received 22 May 2015; accepted 23 June 2015; published 26 June 2015

Copyright (C) 2015 by authors and Scientific Research Publishing Inc.

This work is licensed under the Creative Commons Attribution International License (CC BY).

http://creativecommons.org/licenses/by/4.0/

(c) (i) Open Access

\begin{abstract}
This article sets to study the reactions of student teachers towards students' disruptive behaviors in high school. A delayed video-scopic analysis has been performed using the "Disciplinary Incidents Analysis System" (Brunelle, Brunelle, Gagnon, Goyette, Martel, Marzouk, \& Spallanzani, 1993). A total of 1379 reactions to disruptive behaviors have been recorded in Tunisian student teachers enrolled in the last year of their teacher education in the License-Masters-Doctorate (LMD) system. The results show a clearly low level of student teachers' intervention since they frequently opt for ignorance of disruptive behavior. In fact, a high predominance of the reaction "ignore" (56.9\%) qualifies these interventions, while interactive reactions are seldom used (17.4\%). Following these results, a readjustment is probably required in both the practical and theoretical parts of teacher education of Tunisian student teachers. This may occur by making teaching disruptive behaviors' management at school part of the curriculum.
\end{abstract}

\section{Keywords}

Physical Education, Student Teachers, Educational Approach, Disruptive Behaviors

\section{Introduction}

Disruptive behavior management constitutes a major concern among teachers, beginner teachers and also stu-

How to cite this paper: Maddeh, T., Hermessi, S., Bennour, N., \& Souissi, N. (2015). Student Teachers' Reactions Responding to Students' Disruptive Behaviors: A Case Study in High School Education in Tunisia. Creative Education, 6, $1121-1128$. http://dx.doi.org/10.4236/ce.2015.611110 
dent teachers (Desbiens, Turcotte, Spallanzani, Roy, Tourigny, \& Lanoue, 2011). This statement bears on the fact that the failure or success of a teacher is closely linked to classroom order (Siedentop, 1994). In fact, for many years, teachers have considered dealing with disruptive behaviors as the main indicator of good performance in teaching (Desbiens, Turcotte, Spallanzani, Roy, Tourigny, \& Lanoue, 2011; Doyle, 1986; Siedentop, 1994).

Legault (1999) confirms this theory and adds that students' disruptive behavior is listed as being among the most important problems student teachers have to deal with because it causes both loss of control over students and a considerable loss of time (Opinel, 2001; Supaporn, Dodds, \& Griffin, 2003). These weaknesses are the result of a lack in cognitive and procedure knowledge required to keep order coupled with non-operational representations and lack of know-how in building relationships with students (Desbiens et al., 2008, 2011).

In fact, the lack of experience of student teachers makes them very often much more concerned with their survival in relation to the class as a group. They pay attention to things that matter to them individually such as classroom observation by authorized teacher trainers and supervisors, the fear of failure, the feeling of professional lack of concern and motivation as well as class control. These concerns have inevitably caused student teachers to forget about one of the most important sides in teaching, which is the notion of keeping order in class (Chouinard, 1999; Fortier et Desrosiers, 1991).

Similarly, Fernandez-Balboa (1991) speaks about a chronic inability to deal with disruptive behavior occurring in physical education courses. This inability makes the student teacher feel less and less able to face these problems, which constitutes a big threat for her/him on all levels. Bandura (2007) and Morin \& Battalio (2004) on their side argue that this incapacity has an effect on the feeling of self-efficiency of the trainee. Besides, Archambault \& Chouinard (2003) link this inability to the question of the destruction of one's self-image and motivation to teach, thus putting at stake the student teacher' career choice (Desbiens et al., 2011). This may sometimes lead to career switching (Bouchard, 2007; Kearney, 1987).

Disruptive behaviors divert students' attention from what they are supposed to learn and harm learning achievement at school (Morin \& Battalio, 2004). In fact, these behaviors sometimes lead to a considerable reduction of learning opportunities by creating competitive alternative directions to the program's initial action (Supaporn et al., 2003)

Kulinna (2007-2008) affirms that disruptive behaviors constitute a big threat for good class management, thus encouraging to find appropriate ways to make the disruptive elements behave in an appropriate way in class in order to prepare them to live a future life as good citizens in society (Lewis, Romi, Qui, \& Katz, 2005).

However, in spite of the importance given to the management of disruptive behavior in teacher education for student teachers (Desbiens et al., 2008, 2009, 2011; Gaudreau, 2011), in many countries (Canada, The United States of America and France) we haven't so far found any subject in the university curriculum that prepares Tunisian physical education student teachers to manage and prevent disruptive behavior.

For these reasons, we think it is preferable to bring more knowledge to this relegated field in Tunisia so as to better determine the knowledge the Tunisian physical education teachers need for a better management of disruptive behaviors in their classes.

In this article, our main concern is to identify the types of intervention advocated by Tunisian physical education student teachers when dealing with their students' disciplinary incidents.

\section{Theoretical Framework}

In literature, Goyette, Doré, \& Dion (2000) argue that student teachers' reactions could be considered as a means to counter and target the appearance of disruptive behaviors. Artaud (1989) identifies 12 reactions as a result of the analysis and interpretation of student teachers' reactions to disruptive behaviors in their classes. He classified them in three types of pedagogy: authoritarian, permissive, and interactive pedagogy. The authoritarian pedagogy includes the reactions: "dictate a behavior", "reprimand" and "designate a consequence".

In this type of pedagogy, Brunelle et al. (1993) argue that it is based on a reaction of dominance where the teacher dominates her/his students on the basis of rules that the dominated must imperatively abide by. However, many authors (Artaud, 1989; Reeves, 2002) denounce the use of this type of pedagogy as it hinders students' creativity as well as the opportunity to experiment with multiple choices. In other words, this type of pedagogy does not allow them any freedom. The teacher is at the center of the teaching process.

Permissive behavior, on the other hand, includes the reactions: "make a reminder" and "ignore". 
In contrast to the above stated type, permissive pedagogy considers the student as the center of the teaching process. This permissive behavior which is characterized by laissez-faire as well as the principle of ambiguous commands has led many authors to consider it as problematic (Artaud, 1989; Reeves, 2002).

Last, the interactive pedagogy is subdivided into 2 approaches: the affirmative approach and the open approach. The affirmative approach comprises the reactions: "apply a consequence" and "give reason". The open approach includes the reactions: "describe behavior", "express feelings", "find an arrangement" and "encourage".

This type of pedagogy takes into consideration the student's needs in developing her/his personality. It relies on finding a balance between teacher and student by mutual understanding on the basis of a given set of rules. The compromise between teacher and student constitutes the highpoint of this type of pedagogy. In fact, it encourages students' autonomy instead of trying to control. This will ultimately provide the basis for a future social life which promotes thinking as well as the foundations of discernment (Artaud, 1989; Reeves, 2002).

The literature testifies to the existence of many studies (Brunelle, Brunelle, Martel, Goyette, \& Gaadan, 1995; Dervaux, Carlier, \& Gérard, 2004) that are interested in the way in which physical education student teachers deal with disruptive behaviors. Although these studies have not used the "Disciplinary Incidents' Analysis System", they heavily rely on overall self-observation and written simulation. The studies (Cloes, Demblon, Pirottin, Ledent, \& Piéron, 1998; Piéron \& Emonts, 1998) that have advocated other research methods also highlight physical education student teachers' difficulty in dealing with disruptive behaviors.

In the Tunisian context, Ben Chaaben-Abdennader's (2007) pioneering studies have raised the issue of the Tunisian student teachers enrolled in the License-Masters-Doctorate (LMD) system witnessing some difficulty in classroom organization and planning. These difficulties are best clear in poor class management. The author has also shown that student teachers' education is insufficient to face real student difficulty such as disruptive behaviors. In fact, Tunisian student teachers' practice is characterized by a poor course time management. This leaves them with little time to motor engagement. The author equally argues that Tunisian physical education student teachers are much more focused on the content to be transmitted and forget important sides such as dealing with unexpected incidents in the class group and especially students' disruptive behaviors.

Having resorted to a questionnaire has shown that Tunisian student teachers think they are able to manage disruptive behaviors by such acts as encouraging students $(46,41 \%)$, by obliging them to react to action (24\%) or by adjusting the instructions $(20.25 \%)$. A low percentage of student teachers think they react to disruptive behaviors by criticizing or ignoring them.

The researcher also reports that two thirds of student teachers always choose to punish undisciplined students, thus illustrating authoritarian pedagogy.

In fact, the reactions or penalizing reactions of the authoritarian traditional schooling system take the lead over communication strategies or over what Artaud (1989) calls interactive pedagogy. The author reports two types of reactions by student teachers. The first concerns the category that react $(40.3 \%)$ by using the following types: inhibition or authoritarian $(26.9 \%)$, indulgence $(4.5 \%)$ and finally inciting $(9 \%)$. While the second type concerns those who don't react to disruptive behaviors (59.7) either by not seeing the incident $(35.8 \%)$ or by choosing not to intervene and ignore it (23.8\%). The author has thus reached the conclusion that Tunisian physical education student teachers experience a great difficulty in reacting towards or managing disruptive or unexpected behaviors of high school students.

As far as "Disciplinary Incidents Analysis System" studies are concerned, we refer to those accomplished by Desbiens et al. $(2009,2011)$ which assert that physical education student teachers do not present the required cognitive skills to deal with disruptive behaviors. In fact, student teachers represent a lack of synchrony between the analysis of the situation experienced and the one subsequently analyzed. The shift existing between these two steps in analysis confirms the existence of a weakness at the level of student teachers' reflexive thinking. Besides, the author argues that student teachers rely on non-operating schemes in dealing with indiscipline in schools. These student teachers rather focus on low intensity disruptive behaviors with the underlying purpose of resolution. However, high intensity disruptive behaviors is either ignored or not seen at all.

This finding has been addressed by Chouinard (1999) who has already asserted that student teachers register very often a strong weakness in classroom management linked to non-operating representations in relation to students, to the learning process, to content organization and planning. The author asserts that student teachers' behavior is always marked by a lack in their cognitive automatisms and knowledge of the procedures which lead to problem resolution in order to maintain order in class, the ultimate objective being that students are better involved in the required tasks allotted to them. 
This finding further consolidates the thesis of student teachers' weakness in dealing with disruptive behaviors. In fact, this reasoning has been asserted by Florence, Brunelle, \& Carlier (1998) showing that student teachers personally react to disruptive behaviors instead of relying on an educational intervention model.

However, Goyette et al. (2000) assert that, in general, student teachers advocate authoritarian management style with a percentage of $73.6 \%$ for all types of behaviors. Student teachers rarely use the interactive management style $(26.4 \%)$ to deal with disciplinary incidents. In fact, the authors claim that this choice could be explained by the fact that student teachers prefer direct intervention called authoritarian. This type of intervention provides a short cut to disruptive behaviors which is contrary to indirect intervention called interactive which needs much more time.

Besides, Flavier, Bertone, Méard, \& Durand (2002) have shown that student teachers always choose either to rapidly stop disruptive behaviors without really trying to understand the reason behind them, or to close their eyes by making as if they did not see what was happening. This action is intended to continue student supervision without disturbing the course and this by setting a favorable teaching environment.

Disciplinary problems are ended by targeting one student or the whole group of disruptive students. This reaction is thought to promote teaching dynamics in class.

More recently, Desbiens et al. (2011) has confirmed that physical education student teachers tend to ignore disruptive behaviors with a level of $59 \%$ for the total number of perceived instances. The researcher highlighted the fact that physical education student teachers generally use authoritarian reactions (34.1\%), especially for the category which corresponds to "dictate a behavior" with a percentage of $32.8 \%$. However, the interactive reactions have been the less used ones by student teachers $(6.4 \%)$.

These results go hand in hand with the studies conducted by Nault \& Lacourse (2008) who corroborate these same findings, thus backing the thesis that student teachers advocate a very reduced range of efficient reactions to the management of disciplinary incidents.

Older studies (Brunelle et al., 1995; Dervaux et al., 2004) have already dealt with the same topic and have affirmed that physical education student teachers prefer to intervene to disruptive behaviors by choosing the authoritarian style (46.7\%). This type of intervention is intended to give more self-confidence as well as the impression of having a better control over their classes. The studies also show that using interactive style is relegated to a second position with a percentage reaching $46 \%$. The last place is occupied by permissive style in dealing with disciplinary incidents $(18.8 \%)$.

\section{Methodology}

Our case study concerns 28 Tunisian male physical education student teachers. The latter represent $11.8 \%$ of the population under study $(n=236)$. All of them are in the last year of their teacher education i.e. graduation year enrolled in License-Masters-Doctorate (LMD). All these student teachers attend a practical training in high school context. All the participants in this case study have been informed of our research objectives. They have also been informed of the provisions taken to preserve their anonymity and the confidential aspect of the data. 650 high school students participated in this study: 360 male students (55.3\%) and 290 female (44.7\%). An average of 23.21 students per class has been registered. The student age group under study ranges from 13 to 14 and represent respectively $70.6 \%$ and $29.4 \%$. All students have been engaged in collective sports activities in their schools. Besides, we have used 28 schools representing $14.2 \%$ of the schools total number $(n=40)$.

We have used two Sony video cameras (Handcam 4k) with integrated projectors and a wireless microphones with receivers and transmitters of the brand Boom Tone DJ (VHF 10HL F4 Micro H.F) of a reach of a radius of one hundred meter to capture the verbal interventions of student teachers.

Data collection has been done by two intermediary cameras and a wireless microphone. The two cameras are in diagonally-opposed positions so as to film the whole area where the class session takes place, condemning both blind spots. One of the cameras is connected to the wireless microphone carried by the student teacher with a receiver transmitter of a 100 meter radius reach. Data collection is performed over a period of three weeks. A total of 28 class sessions of 55 minutes each has been filmed.

Data analysis relies on the technique of recorded observation using the "Disciplinary Incidents Analysis System" borrowed from Brunelle et al. (1993).

The Student teachers' reactions analysis in front of disciplinary incidents has been performed as indicated by these same authors by strongly referring to the "Disciplinary Incidents Analysis System". This system allows the 
description of disciplinary incidents also labeled disruptive behaviors that occur during physical education classes. It has seven categories presented as follows:

1. Lesson time;

2. Number of students involved;

3. Level of intensity of disruptive behaviors;

4. Disruptive behaviors effect;

5. Types of reactions to disruptive behaviors;

6. Effect of reactions to disruptive behaviors;

7. Access or lack of access to disruptive behaviors by the person involved.

In this study, we limit our work to category 5 which refers to types of teachers' reactions towards disruptive behaviors and try to provide a fine analysis of them.

The "Disciplinary Incidents Analysis System" is a system of observation having a set of predetermined categories. It identifies and describes the content of disciplinary incidents, of which are disruptive behaviors that may occur in physical education classes. The "Disciplinary Incidents Analysis System" is based on a strategy of event observation that is to say the disciplinary incidents are noted down along their time of occurrence during a class session. This system of observation has proved that it is robust. At the time of elaboration, six encoders had to confront their perceptions linked to ten disciplinary incidents and to each of the 70 encoding decisions associated to them. The inter-analysis loyalty percentage obtained at that moment was as high as $88 \%$.

For the analysis and interpretation of reactions of teachers, we refer to the three types of pedagogy defined by Artaud (1989) in the preceding section (authoritarian, permissive, and interactive pedagogy).

Using "Disciplinary Incidents Analysis System" could be summarized as a direct observation of video records in order to present our encoding on our observation grid. Each recording is carefully analyzed addressing the different teacher interventions.

To make sure that inter encoding is reliable, two other researchers have been trained to use "Disciplinary Incidents Analysis System" encoding procedures over the whole 2014 school year. The confrontation of their perception of the different results after the encoding of the same teaching class session provided $87 \%$ rate of concordance over the 20 disciplinary incidents that occurred. This inter encoding concordance rate is considered as reliable according to Fortin, Schweickert, Gaudreault, \& Viau-Quesnel (2010).

\section{Results and Discussion}

Absolute and relative frequencies of Tunisian student teachers' interventions highlight the dominance of interventions which fall under permissive pedagogy. The interventions reflecting the latter present $61.3 \%$ represented by 832 interventions of which 784 "ignore" (56.9\%) and 48 "make a reminder" (3.4\%). These results are in alignment with those of Desbiens et al. (2009) that highlight the use in priority of the action "ignore" by these student teachers with $59.5 \%$ of interventions.

Besides, the interventions revealing an authoritarian pedagogy represent $22.3 \%$ of the total. We have registered 307 interventions of which 116 of the type "dictate a behavior" (8.4\%), 139 of the type "reprimand" $(10.1 \%)$ and 52 of the type "designate a consequence" (3.8\%).

Finally, the interventions revealing an interactive pedagogy are places in final position. On a total of 240 interventions (17.4\%), 172 belong to the category "describe behavior" (12.4\%) while the 68 other interventions belong to the category "apply a consequence" $(5 \%)$.

These results show that student teachers facing students' disciplinary incidents appeal in priority to permissive pedagogy type interventions. The authoritarian or interactive pedagogy types are undervalued. Table 1 recapitulates the quantitative data of our main results.

The results obtained reveal physical education Tunisian student teachers' difficulties in dealing with disciplinary incidents during physical education class sessions that are rather agitated. In fact the high frequency of interventions reaching an average of $49.25 \%$ per session interventions, accentuates doubt on the ability of Tunisian student teachers to bring order in the classroom.

The interventions occur with a rate of 0.89 every minute. Not only do these results corroborate Desbiens et al. (2008) which signal a great weakness among student teachers in dealing with disciplinary incidents but also highlight the fact that student teachers' situation in Tunisia is far more alarming.

We make the hypothesis that Tunisian student teachers do not have the necessary background in knowledge 
Table 1. Relative frequency (f) and absolute frequency (f \%) of Tunisian student teachers' pedagogical interventions.

\begin{tabular}{lcc}
\hline Reactions & f & f \% \\
\hline Authoritarian pedagogy & 116 & $8.4 \%$ \\
Dictate a behavior & 139 & $10.1 \%$ \\
Reprimand & 52 & $3.8 \%$ \\
Designate a consequence & & \\
Permissive pedagogy & 48 & $3.4 \%$ \\
Make a reminder & 784 & $56.9 \%$ \\
Ignore & & \\
Affirmative interactive pedagogy & 68 & $5 \%$ \\
Apply a consequence & 0 & $0 \%$ \\
Give reason & & \\
Open interactive pedagogy & 172 & $12.4 \%$ \\
Describe behavior & 0 & $0 \%$ \\
Express feelings & 0 & $0 \%$ \\
Find and arrangement & 0 & $0 \%$ \\
Encourage & 1379 & \\
The total of encoded interventions & & \\
\hline
\end{tabular}

and know-how in other words, the theoretical and practical knowledge required to deal with in an efficient way disruptive behaviors.

Many other studies (Ben Chaaben-Abdennader, 2007; Chouinard, 1999; Cloes et al., 1998; Desbiens et al., 2008, 2009, 2011; Gaudreau, 2011; Piéron \& Emonts, 1998) consolidate our results and confirm student teachers' difficulty in creating a favorable learning environment in spite of the existence of specialized and intensive trainings in disciplinary incidents' management for the same category of teachers.

Our results also advocate that physical education Tunisian student teachers are much more focused on the organization as well as setting up of learning situations at the expense the fundamental aspects of classroom management such as the notion of order (Chouinard, 1999). These results corroborate Ben Chaaben-Abdennader's (2007). The author argues that Tunisian student teachers tend to focus on the content to be transmitted and forget important sides such as getting prepared to unexpected incidents and managing incidents made by the class group.

Moreover, as our results explanatory hypothesis stipulates, highlighting Tunisian student teachers' lack of knowledge in dealing with disciplinary incidents makes them most of the time ignore disruptive behaviors so as not to disturb the proper conduct of their class sessions. In fact, studies completed by Flavier, Bertone, Merad, \& Durand (2002) confirm our explanation by adding that teachers have a tendency to sometimes close their eyes when facing students' transgressions in order to avoid direct conflict, which may affect the course of the lesson.

On the other hand, our results point to the restrained use of interactive pedagogy interventions (17.4\%). These results go against what many authors (Artaud, 1989; Reeves, 2002) think of this pedagogy. According to them, the latter favors the development of balance between teachers and students. It also maintains the students balance by improving the foundations of thinking and this for a better preparation of future life in society.

Teachers also opt for authoritarian interventions (Brunelle et al., 1995; Dervaux et al., 2004) which testify their anchorage in the old school practices which rapidly put an end to disciplinary incidents that appear in class (Flavier et al., 2002). These findings join those of Goyette et al. (2002) and those of Ben Chaaben-Abdennader (2007) advancing the idea that we always witness "the alliance of empiricism and charisma that relate to traditional conceptions of school: it is gift confronted to experience that makes a pedagogue and students' learning is 
primarily the result of her/his authority".

The Tunisian student teachers' use of permissive pedagogy summarized in ignoring disciplinary incidents (Flavier et al., 2002) proves to be a very serious matter because this type of interventions is synonymous with their weakness in dealing with disciplinary incidents. Desbiens et al.'s (2009) study consolidates our results bringing about the fact that student teachers do not have necessary skills and knowledge to manage disruptive behaviors when they appear.

Taking into account the findings concerning Canadian student teachers having received a teacher education in dealing with disciplinary incidents in school context during their university track, the results obtained in Tunisia through this study constitute a serious problem to which teacher education is to find remedies.

\section{Conclusion}

In our study, the results indicate that the very high number of interventions occurring during the observed physical education classes can be explained not only by the nature of the classes themselves that are characterized by some agitation, but also by the difficulty experienced by student teachers who have hardly any skill in maintaining class order.

Being confronted with students' disruptive behaviors, student teachers try either to manage as they can, knowing that they don't have any theoretical and practical knowledge to do it, or to ignore due to be afraid of the consequences on the general course of the class session and the classroom environment.

The results invite us to implement an emergency plan whose objective is to find sound procedures to master and manage disciplinary incidents in the school environment. In fact, the prospects for initial and continuing training would be a great contribution to student teachers' professional life.

\section{References}

Archambault, J., \& Chouinard, R. (2003). Towards an Educational Classroom Management (2nd ed.). Montreal: Gaetan Morin.

Artaud, G. (1989). The Educational Intervention. Beyond Authoritarianism and Leave Doing. Ottawa: Les presses de l'Université d'Ottawa.

Bandura, A. (2007). Self-Efficacy: The Feeling Personal Effectiveness (2nd ed.) (J. De Lecomte, Trans.). Paris: De Boeck.

Ben Chaaben-Abdennader, Z. (2007). Say, Do and Transmit: The Teacher Education of Physical Education in Tunisia. Ph.D. Thesis in Sports Science, Motor Skills and Human Movement, Paris: University of Paris.

Bouchard, S. (2007). Act to Facilitate Insertion of Teachers. Nouvelles CSQ, 28, 24-25.

Brunelle, J., Brunelle, J.-P., Gagnon, J., Goyette, R., Martel, D., Marzouk, A., \& Spallanzani, C. (1993). System Disciplinary Incidents (Version 3). Intervention Research Group in Physical Activity (GRIAP), Department of Physical Education, Faculty of Education, Quebec: University Laval.

Brunelle, J., Brunelle, J.-P., Martel, D., Goyette, R., \& Gaadan, M. (1995). Disciplinary Incidents That Challenge the Most of Physical Education Students. In C. Paré (Ed.), To Better Teaching Physical Education? Think About It! (pp. 301-313). Trois-Rivieres: University of Quebec at Trois-Rivières.

Chouinard, R. (1999). Beginning Teachers and Classroom Management Practices. Review of sciences de l'éducation, XXV, 497-514. http://dx.doi.org/10.7202/032011ar

Cloes, M., Demblon, S., Pirottin, V., Ledent, M., \& Piéron, M. (1998). Characterization of the Most Significant Discipline Incidents Experienced by Physical Education Teachers. Review of l'Education physique, 38, 59-72.

Dervaux, P., Carlier, G., \& Gérard (2004). How Student Teachers Report That They Handle Six Situations of Indiscipline? In M. Locquet, \& Y. Léziart (Eds.), Sports and Artistic Cultures Formalization of Professional Knowledge. Practices, Teacher Education, Research (pp. 229-232). Rennes: University of Haute Bretagne, Rennes II.

Desbiens, J. F., Lanoue, S., Turcotte, S., Tourigny, J. S., \& Spallanzani, C. (2009). Perception of the Appearance Frequency of Disruptive Behavior by Student Teachers of Physical Education and Health. Nouveau cahier de la recherche en éducation, 12, 179-193.

Desbiens, J. F., Turcotte, S., Spallanzani, C., Roy, M., Brunelle, J. P., Tourigny, J. S., \& Lanoue, S. (2008). An Analysis of Disruptive Behavior Occurred during Physical Education Classes and Health Taught by Teacher Students. STAPS, No. 81, 73-88.

Desbiens, J. F., Turcotte, S., Spallanzani, C., Roy, M., Tourigny, J. S., \& Lanoue, S. (2011). How Student Teachers of Physical Education and Health React against the Indiscipline of Their Students? Science \& Motricité, 73, 39-54. 
http://dx.doi.org/10.1051/sm/2010014

Doyle, W. (1986). Classroom Organization and Management. In M. C. Wittrock (dir.), Handbook of Research on Teaching (pp. 392-431). New-York: Macmillan.

Fernandez-Balboa, J. M. (1991). Beliefs, Interactive Thoughts, and Actions of Physical Education Students Teachers regarding Pupil Misbehaviors. Journal of Teaching in Physical Education, 11, $59-78$.

Flavier, E., Bertone, S., Méard, J., \& Durand, M. (2002). The Concerns of Physical Education Teachers in the Genesis and Regulation of Classroom Conflicts. Revue française de pédagogie, 139, 107-119. http://dx.doi.org/10.3406/rfp.2002.2886

Florence, J., Brunelle, J., \& Carlier, G. (1998). Teaching in High School Physical Education. Bruxelles: De Boeck University.

Fortier, A., \& Desrosiers, P. (1991). The Personal Concerns of Teachers Students in Physical Education in Elementary School. STAPS Review, 26, 47-59.

Fortin, C., Schweickert, R., Gaudreault, R., \& Viau-Quesnel, C. (2010). Effects of Memory Search and of Task Switching on Concurrent Timing: A Dissociation. Journal of Experimental Psychology: Human Perception \& Performance, 36, 580595. http://dx.doi.org/10.1037/a0017639

Gaudreau, N. (2011). The Management of Inclusive Classroom Behavior Problems: Effective Practices. Education et Francophonie, 39, 122-144.

Goyette, R., Doré, R., \& Dion, E. (2000). Pupils' Misbehavior and the Reactions and Causal Attributions of Physical Education Student Teachers: A Sequential Analysis. Journal of Teaching in Physical Education, 20, 3-14.

Kearney, P. (1987). Experienced and Prospective Teachers' Compliance-Gaining Message Selections on Common Student Misbehaviors. Proceedings of the 73rd Congress of Speech Communication Association, Boston, 5-8 November 1987, 184-290.

Kulinna, P. H. (2007-2008). Teachers' Attributions and Strategies for Student Misbehavior. Journal of Classroom Interaction, 42, 21-30.

Legault, F. (1999). Classroom Management during an Internship Initiation to Education and the Emergence of a Virtual Community Focused on Problem Solving. Revue des sciences de l'éducation, 25, 593-619. http://dx.doi.org/10.7202/032015ar

Lewis, T., Romi, S., Qui, X., \& Katz, Y. J. (2005). Teachers' Classroom Discipline and Student Misbehavior in Australia, China and Israel. Teaching and Teacher Education, 21, 729-741. http://dx.doi.org/10.1016/j.tate.2005.05.008

Morin, J., \& Battalio, R. (2004). Construing Misbehavior: The Efficacy Connection in Responding to Misbehavior. Journal of Positive Behavior Interventions, 6, 251-254. http://dx.doi.org/10.1177/10983007040060040601

Nault, T., \& Lacourse, F. (2008). Classroom Management. A Skill to Develop. Anjou: Les éditions CEC.

Opinel, M. (2001). Impact of the Task Novice School on Competence to Manage a Class. Master's Thesis, Sherbrooke: University of Sherbrooke.

Piéron, M., \& Emonts, M. (1998). Analysis of Disciplinary Problems in Physical Education Classes. l'education physique Review, 28, 33-40.

Reeves, J. (2002). Self-Determination Theory Applied to Educational Settings. In E. L. Deci, \& R. M. Ryan (Eds.), Handbook of Self-Determination Research (pp. 183-204). Rochester, NY: The University Press of Rochester. l'education physique Review, 38, 69-82.

Siedentop, D. (1994). Learning to Teach Physical Education. Montréal: Gaëtan Morin.

Supaporn, S., Dodds, P., \& Griffin, L. (2003). An Ecological Analysis of Middle School Misbehavior through Student and Teacher Perspectives. Journal of Teaching in Physical Education, 22, 328-349. 